\title{
Breast Milk Lactoferrin Regulates Gene Expression by Binding Bacterial DNA CpG Motifs But Not Genomic DNA Promoters in Model Intestinal Cells
}

\author{
PETER MULLIGAN, NICHOLAS R.J. WHITE, GIOVANNI MONTELEONE, PING WANG, JAMES W. WILSON, \\ YOSHI OHTSUKA, AND IAN R. SANDERSON
}

\begin{abstract}
Adult and Paediatric Gastroenterology [P.M., N.R.J.W., P.W., J.W.W., I.R.S.], Institute of Cell and Molecular Science, Barts and The London, Queen Mary's School of Medicine and Dentistry, London E1 2AD, United Kingdom; Dipartimento di Medicina Interna [G.M.], Università Tor Vergata, 1-00133 Rome, Italy; Department of Pediatrics [Y.O.], Juntendo University, Tokyo 113-8421, Japan
\end{abstract}

\begin{abstract}
High-affinity binding of DNA by lactoferrin (LF) is an established phenomenon, but the biologic function of this interaction remains unclear. LF is an abundant breast milk protein (12.5-87.5 $\mu \mathrm{mol} / \mathrm{L}$ ) and is resistant to digestion in the infant gut. Regulation of gene expression by LF appears to be a major activity, particularly in modulating immune responses. We hypothesized that LF binding to DNA is a mechanism of gene regulation and aimed to identify the mechanism and physiologic sites of this activity. Our studies focused on two major biologic compartments of DNA: LF binding to proinflammatory bacterial DNA sequences (CpG motifs) in extracellular compartments and LF binding to genomic DNA promoters in the nucleus. LF $0.5 \mathrm{mmol} / \mathrm{L}$ inhibited $\mathrm{CpG}$ motif-induced nuclear factor- $\kappa \mathrm{B}(\mathrm{NF}-\kappa \mathrm{B})$ activation and interleukin (IL)-8 and IL-12 cytokine gene transcription in $\mathrm{B}$ cells. Intestinal epithelial cells were unresponsive to CpG motifs. However, significant LF transferred across $\mathrm{M}$ cell-like monolayers, specialized epithelial cells that transcytose intact macromolecules to underlying B-cell follicles in the intestine. LF did not activate gene expression by binding to putative response elements in epithelial and lymphoid cells. Nor did LF bind to putative response elements specifically in gel-shift assays. No nuclear localization of LF was detected in green fluorescent protein (GFP) tagging experiments. We conclude that breast milk LF regulates gene expression by binding $\mathrm{CpG}$ motifs extracellularly, with follicular B cells in the infant intestine a likely target. (Pediatr Res 59: 656-661, 2006)
\end{abstract}

$\mathrm{L}$

$\mathrm{F}$ is a $78-\mathrm{kD}$, iron-binding glycoprotein of the transferrin (TF) family $(1,2)$. It is a major protein of breast milk, ranging in concentration from approximately $87.5 \mu \mathrm{mol} / \mathrm{L}$ in colostrum to $12.5 \mu \mathrm{mol} / \mathrm{L}$ in mature milk (3). It is also found at lower concentrations in the plasma $(10-0 \mathrm{nmol} / \mathrm{L})$, where it is secreted by neutrophils in response to inflammation (4). LF is remarkably stable in the infant intestine due to the resistance of LF to proteolytic degradation (5), the reduced protein digestive capacity of the infant gut, and the presence of $\alpha_{1}$-antitrypsin in milk (3). The intestinal epithelium of the breast-feeding infant is thus exposed to high concentrations of

Received July 11, 2005; accepted December 21, 2005.

Correspondence: Ian R. Sanderson, M.D., Adult and Paediatric Gastroenterology, Institute of Cell and Molecular Science, Barts and The London, Turner Street, London., E1 2AD; e-mail: i.r.sanderson@qmul.ac.uk

This work was supported by the graduate program of St. Bartholomew's and the Royal London School of Medicine and Dentistry and by a grant from the Nutricia Research Foundation.

DOI: 10.1203/01.pdr.0000214958.80011.e1 intact LF. Absorption of intact macromolecules is an established feature of the neonatal intestine (6), and high concentrations $(1.25 \mathrm{nmol} / \mathrm{L}-2.81 \mu \mathrm{mol} / \mathrm{L})$ of structurally intact, DNA-binding breast milk LF have been purified from the urine of preterm infants (7). Receptor-mediated transport of intact LF across intestinal epithelial monolayers in vitro has also been described (8).

LF has immunoregulatory properties (2) and binds a wide range of molecules, and a cell surface receptor has been cloned from intestinal epithelium (9). Furthermore, substantial evidence of gene regulation by LF exists. Examples include inhibition of granulocyte/macrophage colony-stimulating factor (GM-CSF) expression in monocytes and macrophages $(4,10)$, reduction of IL-1 expression in lymphocytes (11), and increased transcription of matrix metalloproteinase-1 (MMP-1) in Jurkat T cells and HeLa epithelial cells (12). Interestingly, although LF binds to DNA with high affinity $\left(\mathrm{K}_{\mathrm{d}}\right.$ $1 \mu \mathrm{mol} / \mathrm{L})(13)$, it contains no recognized DNA-binding motifs. Rather, the LF-DNA interaction appears to rely on charge-charge interactions between the highly basic LF (pI 8.7), particularly four consecutive arginine residues at the extreme N-terminus, and negatively charged DNA.

Observations of DNA binding led to the description of a putative transcription factor activity for LF (14), although no endogenous genes have yet been shown to be regulated by this mechanism. Nevertheless, it is also possible that LF binds to extracellular DNA. Binding of proinflammatory bacterial DNA sequences (unmethylated CpG motifs) by LF has been shown to inhibit B-cell activation (15). Several synthetic DNA oligodeoxynucleotides incorporating $\mathrm{CpG}$ motifs $[\mathrm{CpG}$ phosphoriothioate-protected oligonucleotide $(\mathrm{ODN})]$ replicate the proinflammatory effect of bacterial DNA (16). LF binds to extracellular $\mathrm{CpG}$ ODN and prevents their internalization (15). However, the concentration of LF required to achieve

Abbreviations: EMSA, electrophoretic mobility-shift assays; LF, lactoferrin; LFRE, lactoferrin response element; ODN, phosphoriothioate-protected oligonucleotide; TEER, transepithelial electrical resistance; TF, transferrin 
this was 50 -fold greater than plasma LF, making it unclear whether such an inhibitory mechanism operates in the systemic immune system. Given the extensive exposure of the neonatal intestine to lactoferrin, we hypothesized that human milk LF regulated CpG-motif activity at this site. We also examined nuclear localization, putative promoter DNA binding, and direct transcriptional regulation by LF.

\section{METHODS}

Cell culture. RPMI 8226, Raji, K562, HT-29, and Caco-2 cells were obtained from ECACC (UK) and maintained in Dulbecco modified Eagle medium or RPMI, as appropriate, with $10 \%$ fetal bovine serum and $2 \mathrm{mmol} / \mathrm{L}$ L-glutamine (Life Technologies, UK). RNA was extracted as previously described (17).

$N F-\kappa B$ luciferase reporter gene assays. The NF- $\kappa \mathrm{B}$ luciferase reporter vector (pNF- $\kappa$ Bluc) was transfected into RPMI 8226 B cells using Fugene 6 (Roche, Germany). Two hours after addition of apo-LF, or apo-TF used as an iron-binding control, the cells were stimulated with pro-inflammatory $\mathrm{CpG}$ ODN (TCGTCGTTTTGTCGTTTTGTCGTT) or control (control ODN: (TCCAGGACTTCTCTCAGGTT) for $18 \mathrm{~h}$. CpG ODN and control ODN are identical to ODN 2006 and ODN 1982, respectively, as identified and characterized by Hartmann et al. (16). Results were expressed as the mean of triplicate values $\pm \mathrm{SD}$.

IL-8 enzyme-linked immunosorbent assay (ELISA). Secreted IL-8 was measured using an IL-8 ELISA kit (Amersham Biosciences, UK) according to manufacturer's recommendations. Concentrations were normalized against total protein in the corresponding cell lysates as determined using the BCA assay (Sigma Chemical Co., Dorset, UK). Results were expressed as the mean of triplicate values $\pm \mathrm{SD}$.

$\boldsymbol{L F}$ transcytosis. M cell-like monolayers were grown on 24-mm, 3.0- $\mu \mathrm{m}$ pore Transwell filters (Costar, NY) as previously described (18). Briefly, $10^{6}$ Caco-2 cells (a gift of S. Ghosh, University of London) in $500 \mu \mathrm{L}$ of medium were spread in a meniscus on the underside of the Transwells, which were then inverted and incubated in Caco-2 culture medium for $14 \mathrm{~d}$. Raji B cells were added at $10^{7} / \mathrm{mL}$ to the basolateral chamber of the Transwell. After $3 \mathrm{~d}$ of coculture to allow $\mathrm{M}$ cell-like differentiation to occur, monolayers were washed to remove Raji B cells; $10 \mu \mathrm{mol} / \mathrm{L}$ apo-LF or holo-LF (Sigma Chemical Co.) was added to apical chambers. Human LF concentrations in the basolateral medium were determined using LF ELISA (Calbiochem, UK). The transepithelial electrical resistance (TEER) before and after LF transcytosis was consistently in the range of $700-850 \Omega \mathrm{cm}^{2}$, confirming monolayer integrity.

Measurement of IL-8, IL-12 p40, and $\beta$-actin mRNA. mRNA expression was compared using reverse transcriptase polymerase chain reaction (RTPCR) (17). Primers were as follows: IL-12 p40: AAGGAGGCGAGGTTCTAAGC (exon 2); TCCTTGTTGTCCCCTCTGAC (exon 4); IL-8: TCTGCAGCTCTGTGTGAAGG (exon 1); ATTGCATCTGGCAACCCTAC (exon 4); Beta actin: CGAGGCCCAGAGCAAGAGA (exon 3); CACAGCTTCTCCTTAATGTCACG (exon 4).

LF luciferase reporter assays. Double-stranded inserts were prepared from complementary oligonucleotides (Amersham Biosciences) containing four tandem repeats of either LF response element (RE) 1 (GGCACTTGC) or LFRE2 (ACTACAGTCTACA) with a 5' SacI site and 3' XhoI site (14). Inserts and pGL3P firefly luciferase vector (Promega, UK) were digested with $\mathrm{SacI} / \mathrm{XhoI}$ and the inserts cloned into the vector. Identity of clones containing LFRE inserts was confirmed by Sanger dideoxy sequencing. For promoter exchange experiments, the SV40 promoter was excised and a minimal thymidine kinase promoter (a gift of P. King, University of London) was cloned into the vector. K562 cells were transfected with the luciferase reporter and the pRL-TK vectors and electroporated in cuvettes at $300 \mathrm{~V} / 960 \mu \mathrm{F}$ using a Gene Pulser 2 electroporator (BioRad, UK). Caco-2 cells were transfected with pGL3P-LFRE and pRL-TK vectors using Fugene 6 reagent (Roche, Germany). Cotransfected cells were stimulated for $48 \mathrm{~h}$ with apo-LF or holo-LF (Sigma Chemical Co.). Renilla luciferase values were used to normalize for transfection efficiency (5-15\% of cells).

Electrophoretic mobility-shift assays (EMSA). Double-stranded LFREs were prepared from complementary oligonucleotides (Amersham Biosciences) containing four tandem repeats of either LFRE1 (GGCACTTGC) or LFRE2 (ACTACAGTCTACA) with a 5' SacI site and $3^{\prime}$ XhoI site. LFREs were labeled with $\left[\gamma^{32} \mathrm{P}\right]$, and $0.5 \mathrm{ng}{ }^{32} \mathrm{P}$-LFRE was incubated with $120 \mathrm{ng}$ apo-LF (Sigma Chemical Co.), $1 \mu \mathrm{g}$ poly[dI.dC], 0.05\% TritonX-100, 10\% glycerol, $10 \mathrm{mmol} / \mathrm{L}$ Tris- $\mathrm{HCl}(\mathrm{pH} 7.5), 50 \mathrm{mmol} / \mathrm{L} \mathrm{NaCl}, 0.5 \mathrm{mmol} / \mathrm{L}$ DTT (Sigma Chemical Co.) in a final volume of $20 \mu \mathrm{L}$. To certain reactions, an excess of unlabeled LFRE or unlabeled nonspecific dsDNA (CACAACGCGTGAGCTCTCTAGAAAGCATCATCTCAACACTAACTTGATAATTAAGTGCCTCGAGCACA) was added at the same time as the labeled LFRE, with the LF being added subsequently. The binding reactions were incubated for $30 \mathrm{~min}$ at room temperature. The nonspecific DNA sequence bore no sequence homology to either of the LFRE probes. Samples were electrophoresed on $5 \%$ polyacrylamide gels.

Enhanced GFP tagging. Full-length human LF cDNA was obtained from the IMAGE Consortium (IMAGE clone number 4150967, HGMP, UK) and sequence identity confirmed by Sanger dideoxy sequencing. EGFP and LF cDNAs were prepared from pEGFP(N3) (Clontech, UK) and IMAGE clone 4150967, respectively, using PCR. For pGFP-LF(N), the following primers were used: LF cDNA FW: CGTATACGATAAGCTTGGCCGTAGGAGAAGGAGTGTT; LF cDNA RV: CGTATACGAGCGGCCGCGGCCATCTTCTTCGG; GFP cDNA FW: CTGGTTTAGTGAACCGTCAGATCCG; GFP cDNA RV: CGCGTTACTTAAGCTTGTAACAGCTCGTCC. For pGFP-LF(C), the following primers were used: LF cDNA FW: GTACGGATCCATGGGCCGTAGGA; LF cDNA RV: TTACTTCCTGAGGAATTCAC; GFP cDNA FW: GTACGAATTCCTCAGGAAGGTGAGCAAGG; GFP cDNA RV: CCTCTACAAATGTGGTATGG. pGFP-LF(N) was constructed by cloning BamH1/NotI-digested LF cDNA and EcoR1/NotIdigested EGFP cDNA into empty pEGFP(N3) vector digested with BamH1/ NotI. pGFP-LF(C) was constructed by cloning SacI/HindIII-digested LF cDNA and HindIII/NotI-digested EGFP cDNA into empty pEGFP(N3) vector digested with SacI/NotI. Sequences of both clones were confirmed by Sanger dideoxy sequencing. Cells were transfected with pGFP-LF vector as per LFRE luciferase assays. Transfected cells were stimulated with 10 or 100 $\mathrm{nmol} / \mathrm{L}$ apo-LF or holo-LF (Sigma Chemical Co.) for 0, 15, 30, 45, or $60 \mathrm{~min}$ before fixing in $4 \%$ paraformaldehyde. They were counterstained with DAPI and mounted on slides using Vectashield (Vector Laboratories, Burlingame, CA). GFP fluorescence and DAPI nuclear staining images were captured using a Leica DMR fluorescent microscope.

\section{RESULTS}

LF inhibits CpG motif-induced $N F-\kappa B$ activation and cytokine gene transcription in $B$ cells. The possibility that LF binds to bacterial DNA and thus affects gene regulation was examined using a NF- $\kappa \mathrm{B}$ luciferase reporter gene assays in B cells stimulated with $\mathrm{CpG}$ motif-containing ODN. A non$\mathrm{CpG}$ motif acted as a control. RPMI $8226 \mathrm{~B}$ cells were chosen because they express Toll-like receptor 9 (Tlr9), which is required for CpG-motif responsiveness (19). Initial experiments were performed to determine whether B cells and intestinal epithelial cells were both responsive to $\mathrm{CpG}$ stimulation. In RPMI 8226 B cells stimulated with CpG ODN in the range 0.01 to $0.05 \mu \mathrm{mol} / \mathrm{L}$, a linear relationship between CpG ODN concentration and NF- $\kappa \mathrm{B}$ activation was observed (Fig. 1A). For subsequent experiments, $0.03 \mu \mathrm{mol} / \mathrm{L} \mathrm{CpG}$ ODN was used to ensure sensitive detection of inhibition of NF- $\kappa \mathrm{B}$ activation. No activation of NF- $\kappa \mathrm{B}$ was observed when cells were stimulated with control ODN concentrations up to $1 \mu \mathrm{mol} / \mathrm{L}$, indicating that the response is $\mathrm{CpG}$ motif specific (data not shown). The responsiveness of the intestinal epithelial cell lines Caco-2 and HT-29 to CpG-motif stimulation was investigated by measuring the induction of IL-8, which is potently induced by NF- $\kappa \mathrm{B}$ in these cell lines. Neither cell line was responsive to $\mathrm{CpG}$ ODN stimulation, as determined by IL-8 ELISA (Fig. 1B). Prestimulation with $5 \mathrm{mmol} / \mathrm{L}$ butyrate, which enhances chemokine response to lipopolysaccharide and IL-1 (17), did not result in a response to $\mathrm{CpG}$.

We then investigated LF inhibition of CpG-induced NF- $\kappa \mathrm{B}$ activation in B cells. When RPMI 8226 B cells were preincubated with $0.5-4.0 \mu \mathrm{mol} / \mathrm{L}$ apo-LF for $1 \mathrm{~h}$ before stimulation with $\mathrm{CpG}$ for $16 \mathrm{~h}$ (to ensure $\mathrm{LF}$ presence before addition 


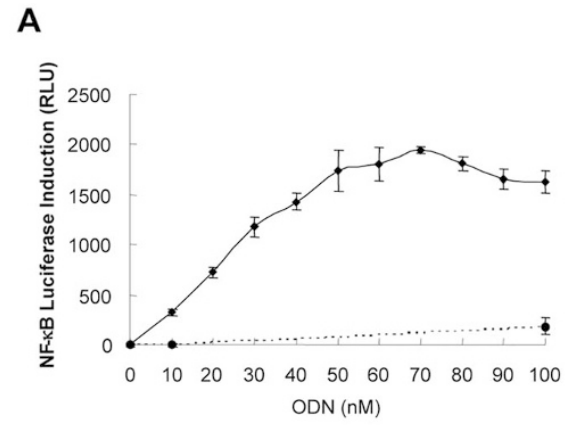

B

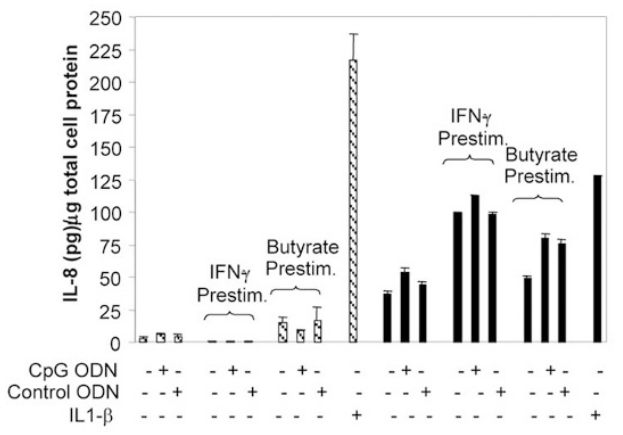

C
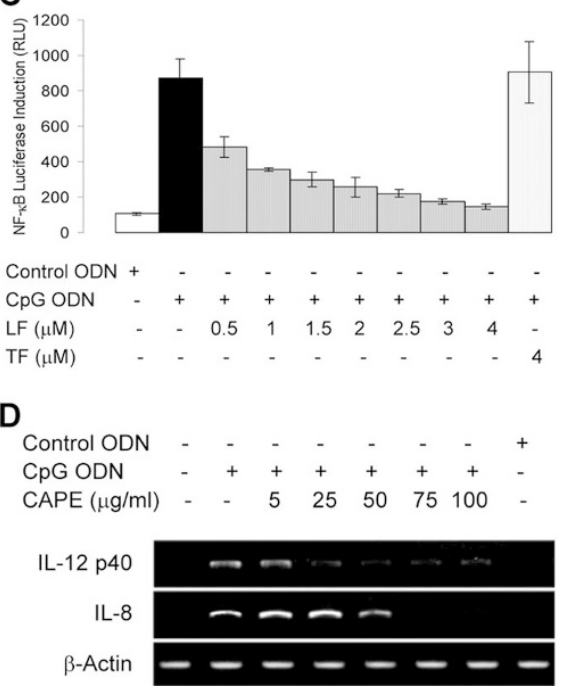

E

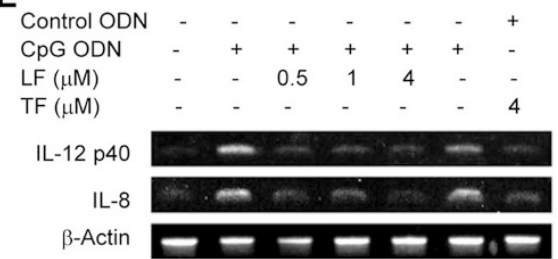

Figure 1. LF inhibits NF- $\kappa$ B activation and transcription of NF- $\kappa \mathrm{B}-$ regulated cytokines induced by $\mathrm{CpG}$ ODN in RPMI $8226 \mathrm{~B}$ cells. (A) NF- $\kappa \mathrm{B}$ luciferase assays in transfected RPMI 8226 B cells demonstrated that $\mathrm{CpG}$ ODN (solid line) induces a linear activation of NF- $\kappa \mathrm{B}$ in the range of 0.01 to 0.05 $\mu \mathrm{mol} / \mathrm{L} \mathrm{CpG}$ ODN. No activation was observed when cells were stimulated with control ODN (broken line). (B) No activation of IL-8 expression was observed in HT-29 (shaded bars) and Caco-2 cells (solid bars) stimulated with $1 \mathrm{mmol} / \mathrm{L} \mathrm{CpG} \mathrm{ODN.} \mathrm{IL-1} \beta$ ( $2 \mathrm{ng} / \mathrm{mL}$ ) was included as a positive control for IL-8 activation. (C) RPMI 8226 B cells transfected with an NF- $\kappa$ B luciferase reporter gene construct were preincubated with apo-LF for $1 \mathrm{~h}$ before stimulation with $30 \mathrm{nmol} / \mathrm{L} \mathrm{CpG}$ ODN. Significant inhibition of NF- $\kappa$ B activation was observed at apo-LF concentrations $\geq 0.5 \mu \mathrm{mol} / \mathrm{L}$, with complete inhibition at $4.0 \mu \mathrm{mol} / \mathrm{L}$. No inhibition was observed with $4.0 \mu \mathrm{mol} / \mathrm{L}$ apo-TF. RLU: Relative luciferase units. Mean \pm SD of triplicate samples $(A-C)$. $(D)$ Incubation of RPMI $8226 \mathrm{~B}$ cells with the NF- $\kappa \mathrm{B}$ inhibitor CAPE inhibited CpG ODN-induced IL-8 and IL-12 p40 gene transcription, as determined by RTPCR. (E) LF inhibited CpG motif-induced IL-8 and IL-12 p40 gene transcription in RPMI 8226 B cells. No inhibition was observed with $4.0 \mu \mathrm{mol} / \mathrm{L}$ apo-TF. The results shown are representative of three separate experiments. of $\mathrm{CpG}$ ), significant inhibition of NF- $\kappa \mathrm{B}$ activation was observed (Fig. 1C) (15). No effect was observed when apo-LF was replaced by apo-TF, even though they share $61 \%$ amino acid homology, suggesting the effect is LF specific. Next, we investigated the effect of LF inhibition of CpG motif-induced NF- $\kappa$ B stimulation on transcription by RT-PCR in stimulated RPMI 8226 B cells. IL-8 and IL-12 p40 were chosen because the critical role of NF- $\kappa \mathrm{B}$ in their expression in B cells is well documented. Preincubation of RPMI 8226 B cells with the NF- $\kappa$ B inhibitor CAPE strongly inhibited up-regulation of IL-8 and IL-12 p40 transcription (Fig. 1D), confirming that regulation of these genes by CpG-motif DNA is strongly dependent on NF- $\kappa$ B activation. When RPMI 8226 B cells were preincubated with $0.5-4.0 \mu \mathrm{mol} / \mathrm{L}$ apo-LF for $1 \mathrm{~h}$ before stimulation, marked inhibition of CpG-induced IL-8 and IL-12 p40 mRNA expression was observed (Fig. 1E). Again, no inhibition was observed when apo-LF was replaced with apo-TF.

LF is transcytosed by model M cells. Because lymphocytes reside beneath the epithelium, we investigated the transcytosis of LF across a model M-cell monolayer (18). Concentrations of $L F$ in the range of $0.5 \mu \mathrm{mol} / \mathrm{L}$ were detected in the basolateral medium $9 \mathrm{~h}$ after addition of $10 \mu \mathrm{mol} / \mathrm{L} \mathrm{LF}$ to the apical chamber (Fig. 2). This suggests that LF could directly interact with B cells in the underlying Peyer's patches.

LF does not activate gene transcription by binding putative LFREs. To examine whether LF could act as a transcription factor by binding DNA in the nucleus, K562 myeloge-

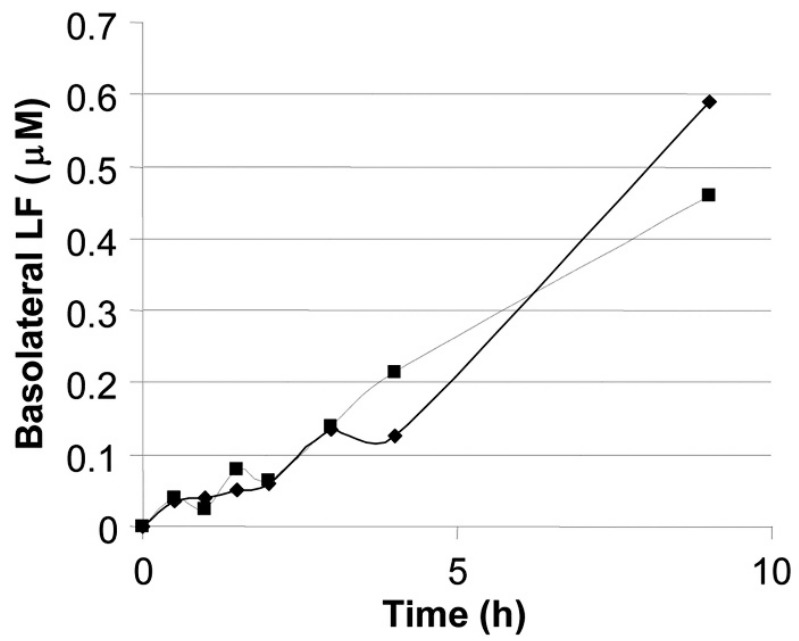

Figure 2. Transcytosis of LF across an M cell-like monolayer. Immunoreactive LF was transcytosed across an $\mathrm{M}$ cell-like monolayer in a timedependent manner. After $9 \mathrm{~h}$, basolateral concentrations of LF in the range of 0.5 to $0.8 \mu \mathrm{mol} / \mathrm{L}$ were achieved when the apical LF concentration was $10 \mu \mathrm{mol} / \mathrm{L}$. Equivalent results were observed for apo-LF (solid line) and holo-LF (broken line), suggesting that iron saturation had no significant effect. TEER values before and after LF transcytosis were consistently in the range of $700-850 \Omega \mathrm{cm}^{2}$.

nous leukemia cells and Caco-2 intestinal epithelial cells were chosen to represent the targets of neutrophil-derived plasma LF and breast milk LF, respectively. Both forms of LF are biochemically identical, except only milk LF is fucosylated. 
As previous reports on transcriptional activation by LF have used the milk form (15), we used LF isolated from human breast milk (20). LF has been purported to bind three short DNA sequences specifically (LFRE1, LFRE2, and LFRE3), two of which were reported to act as LF-responsive cis-acting elements when cloned upstream of reporter gene promoters (LFRE1 and LFRE2) (15). Therefore, we focused our studies on LFRE1 and LFRE2. Luciferase reporter assays were performed to determine whether exogenous LF could bind LFREs in gene promoters and regulate gene transcription. As iron induces conformational changes in LF that could potentially affect transcription factor activity, cells were stimulated with both iron-saturated (holo-) LF and iron-free (apo-) LF (21). Previous reports indicated that transcriptional activation by LF occurs at an extracellular LF concentration of $10 \mu \mathrm{g} / \mathrm{mL}$ (15). Therefore, cells were stimulated with both 10 and $100 \mu \mathrm{g} / \mathrm{mL}$ of both apo- and holo-LF. As Figure $3 A$ shows, no difference in reporter gene activity was observed between stimulated and unstimulated cells for both K562 and Caco-2 cells. In addition, neither the concentration nor the iron-saturation status of LF affected reporter gene activation. Thus, LF does not regulate transcription by binding LFREs cloned upstream of the SV40 promoter in these cells. To investigate the possibility that the strong SV40 promoter was masking transcriptional activation by LF, a promoter exchange experiment was performed. The SV40 promoter was replaced with a minimal thymidine kinase (TK) promoter, and the luciferase assays were repeated. Again, no difference in reporter gene activity was observed between stimulated and unstimulated cells for both K562 and Caco-2 cells (data not shown), suggesting that the lack of transcriptional activation by LF was not influenced by promoter context. We concluded that exogenous LF does not regulate gene transcription via LFRE binding.

Competitive binding EMSAs were carried out to determine the binding specificity of LF for LFRE1 and LFRE2. The minimum concentration of LF sufficient to induce a band shift was determined to be $120 \mathrm{ng} / 20 \mu \mathrm{L}$ binding reaction, and this concentration was used in subsequent competitive binding experiments. When excess unlabeled LFRE was titrated against labeled LFRE, the intensity of the band shift decreased (Fig. 3B, lanes 3-6). A similar result was observed when an excess of unlabeled nonspecific DNA was titrated against labeled LFRE (Fig. 3B, lanes 7-10). Thus, LF binds nonspecific DNA and LFREs with equivalent affinity. This was supported by densitometry of the band-shift intensities (Fig. 3C). We concluded that LFRE binding by LF is nonspecific. Therefore, the lack of transcriptional activation by LF observed in the luciferase reporter gene assays (Fig. 3A) may be due to lack of specificity of LF binding to LFREs.

Cytoplasmic LF does not translocate to the nucleus. However, it is possible that LF possesses other specific DNA binding sites or nuclear activities. Therefore, we investigated the potential of cytoplasmic LF to localize to the nuclei of K562, Caco-2, and HT-29 cells using GFP tagging of LF. Expression of LF was targeted to the cytoplasm by deleting the secretion signal from the LF cDNA. LF was tagged at either the $\mathrm{N}$-terminus or $\mathrm{C}$-terminus to control for possible inhibition of nuclear translocation due to GFP masking a putative nuclear localization sequence. As Figure $4 A$ illustrates, no nuclear translocation of cytoplasmic LF was observed in K562, Caco-2, and HT-29 cells and identical results were observed for N-terminal and C-terminal tagged LF. An extracellular stimulus is frequently required to induce nuclear localization of cytoplasmic proteins. In previous reports of LF nuclear localization, the only extracellular stimulus was LF itself $(15,22)$. Stimulation of transfected cells with $100 \mathrm{nmol} / \mathrm{L}$ LF for 20, 40, or $60 \mathrm{~min}$ before fixation and staining did not induce nuclear localization of LF, indicating that extracellular LF stimulation is not required to induce nuclear localization of cytoplasmic LF, as shown for K562 cells in Figure 4B. This demonstrates that LF cannot possess transcription factor activity in K562, Caco-2, and HT-29 cells, as it does not lo-
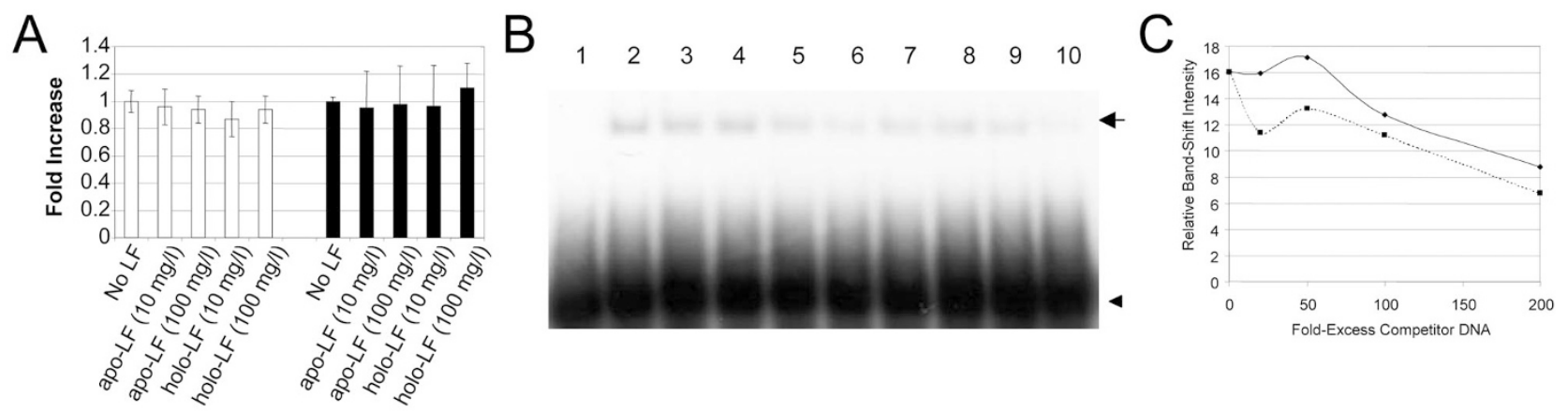

Figure 3. LF does not regulate reporter gene transcription via LFRE binding in K562 or Caco-2 cells and binds putative LFREs nonspecifically. (A) K562 cells (open bars) and Caco-2 cells (solid bars) were transfected with LFRE reporter gene vectors and stimulated with holo- or apo-LF at $10 \mathrm{or} 100 \mu \mathrm{g} / \mathrm{mL}$ for $48 \mathrm{~h}$. Cell lysates were assayed for luciferase activity. No significant difference between unstimulated and stimulated cells was observed for either K562 cells or Caco-2 cells. Results shown are mean \pm SD of three independent experiments. Luciferase values were normalized by expressing luciferase relative to Renilla as a fraction of unstimulated samples. Shown are results for LFRE1; similar results were obtained for LFRE2. (B) Competition-binding EMSAs compared binding of LFRE and nonspecific DNA to LF. Lane 1 is free ${ }^{32} \mathrm{P}-\mathrm{LFRE}$, lane $2{ }^{32} \mathrm{P}-\mathrm{LFRE}$ preincubated with $120 \mathrm{ng}$ apo-LF, lanes 3-6 contain $120 \mathrm{ng}$ apo-LF and 20-, 50,- 100-, and 200-fold molar excess of unlabeled LFRE, respectively; lanes 7-10 contain $120 \mathrm{ng}$ LF and 20, 50, 100, and 200-fold excess nonspecific unlabeled DNA, respectively. Position of the band shift is indicated by the arrow and unbound probe by the arrowhead. Results for LFRE1 are shown; similar results were obtained for LFRE2 and LFRE3. Results are representative of three separate experiments. $(C)$ The intensity of each band in $B$ was quantified by densitometry and plotted against fold excess of unlabeled LFRE (solid line) or nonspecific DNA (broken line). 


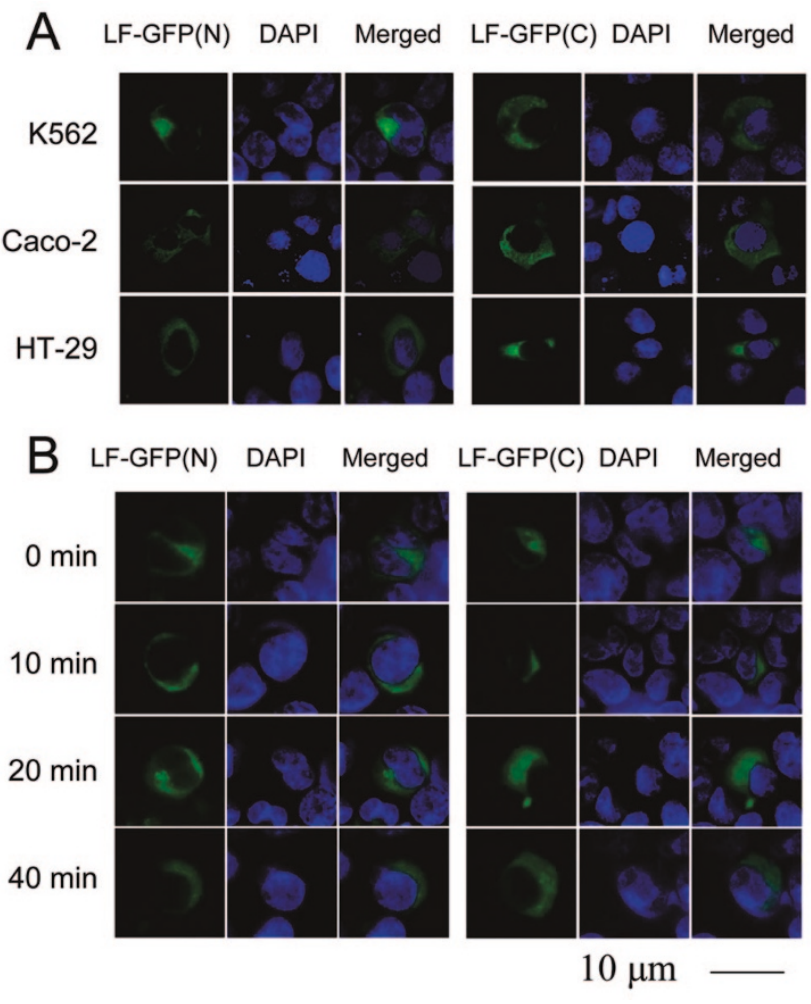

Figure 4. LF does not translocate from the cytoplasm to the nucleus in K562, Caco-2, and HT-29 cells. (A) GFP-tagged LF was expressed in transiently transfected K562, Caco-2, and HT-29 cells and subcellular localization determined by fluorescence microscopy. LF was tagged on either the Nterminus [LF-GFP(N)] or the C-terminus [LF-GFP(C)]. Staining with DAPI revealed the position of the nucleus in both transfected and untransfected cells. Results are representative of three separate experiments. (B) Stimulation of transfected cells with $100 \mathrm{nmol} / \mathrm{L} \mathrm{LF}$ for 20,40 , or $60 \mathrm{~min}$ had no effect on LF-GFP subcellular localization. Shown are results for K562 cells. Similar results were observed for Caco-2 and HT-29 cells. Experiments were repeated three times.

calize to the nucleus. Thus, LF acts on intestinal gene expression by binding to DNA only exterior to cells.

\section{DISCUSSION}

These studies were undertaken to determine whether DNA binding by LF is an important mechanism of gene regulation in the infant intestine. We have shown that binding of extracellular CpG-motif DNA by LF inhibits NF- $\kappa \mathrm{B}-$ regulated gene transcription induced by CpG-motif DNA in B cells. The intestinal epithelium, which is exposed to high concentrations of both bacterial DNA and breast milk LF, is not a prospective site for this activity, as Caco-2 and HT-29 intestinal epithelial cell lines did not respond to CpG-motif stimulation (Fig. 1B). Nevertheless, toll-like receptor (TLR) signaling has been reported in epithelial cells to a variable extent in other studies (23). B cells exhibited significant NF- $\kappa$ B activation when challenged with CpG-motif DNA, as expected. IL-8 and IL-12 cytokine gene transcription was also induced, and this could be inhibited with the specific NF- $\kappa$ B inhibitor CAPE confirming a direct role of NF- $\kappa \mathrm{B}$ in their induction. By first determining the linear range of NF- $\kappa \mathrm{B}$ activation by $\mathrm{CpG}$-motif DNA, we were able to determine the minimum amount of LF required to inhibit CpG-motif induction of NF- $\kappa$ B activation and cytokine gene transcription. This was critical because the LF inhibitory effect is concentration dependent, requiring $\geq 0.5 \mu \mathrm{mol} / \mathrm{L} \mathrm{LF}$.

We chose an in vitro M-cell model to quantify the transcytosis of LF across the intestinal epithelium (18). This model consists of a Caco-2 epithelial cell monolayer grown on a transwell filter cocultured with murine Peyer's patch lymphocytes or human Raji B cells induce the epithelial cells transdifferentiate to an M cell-like physiology, while retaining the overall integrity of the monolayer (18). We demonstrated transcytosis of LF from the luminal to the basolateral compartment in significant concentrations. Allied to substantial evidence demonstrating nonspecific macromolecular uptake across the highly permeable infant intestine (6), specific demonstrations of LF transport by intestinal epithelial cell lines $(64.6 \pm 14.3 \mathrm{ng} \mathrm{LF}$ transported per hour per square centimeter of epithelium, when apical LF concentration was $3.75 \mu \mathrm{mol} / \mathrm{L}$ ) (8) and the purification of structurally intact, DNA-binding breast milk $\mathrm{LF}$ in $\mathrm{nmol} / \mathrm{L}-\mu \mathrm{mol} / \mathrm{L}$ concentrations from the urine of preterm infants (7), there is a convincing case for effective LF concentrations in the lamina propria and lymphoid follicles of the breast-feeding infant intestine.

Bacterial DNA CpG motifs may be present in the lamina propria and Peyer's patches due to lysis of enteropathogens such as Yersinia, Shigella, and Salmonella (24). Evidence of DNA survival in the gut lumen and transcytosis to the lamina propria and Peyer's patches of adult mice has also been reported (25). Thus, LF inhibition of $\mathrm{CpG}$ motif-induced immune gene expression in infant lamina propria B cells is likely to function in vivo. However, such a mechanism is unlikely to operate in the plasma because it requires LF concentrations approximately 50 times as high as plasma concentrations $(10 \mathrm{nmol} / \mathrm{L})$. Although it has previously been shown that LF inhibits CpG-motif DNA-induced B-cell activation by binding to $\mathrm{CpG}$ motif DNA (16), our data are the first to indicate a primary gene regulatory role of the LF-DNA interaction in a biologic context where such mechanisms could operate.

The aim of the second part of our studies was to investigate a putative transcription factor activity for LF. Previous reports have suggested nuclear localization (22) and transcription factor activity of LF in K562 cells (15). We demonstrate that LF cannot activate reporter gene transcription via LFRE binding in K562 and Caco-2 cells. Furthermore, band-shift assays showed that LF bound nonspecifically to putative LFREs. Finally, a direct detection method (GFP tagging and fluorescence microscopy) confirmed that LF does not translocate to the nucleus. GFP tagging has been successfully used to study nuclear localization of diverse nuclear proteins including histones (26), nuclear transport protein Npl3p (27), nucleoporin (28), and centromere-associated proteins Swi6p and CENP-B $(27,29)$ and is presently the method of choice in the study of intracellular trafficking. Tagging of LF on the $\mathrm{N}$ - instead of the C-terminus had no effect on the results, indicating the results were not an artifact of tagging. Therefore, LF does not possess transcription factor activity in K562, Caco-2, and HT-29 cells. 
In conclusion, the interaction between LF and DNA extracellularly is an important mechanism of immune gene regulation, with lymphoid follicles of the infant intestine a likely target of this activity. LF inhibits the CpG-motif DNAinduced activation of NF- $\kappa$ B regulated genes, such as IL- 8 and IL-12, in B cells. This LF is derived from breast milk in the intestinal lumen and may be transcytosed by $\mathrm{M}$ cells. However, no interaction between LF and DNA occurs in the nuclei of K562 lymphocytes or Caco-2 and HT-29 epithelial cells.

Acknowledgments. We acknowledge the assistance of and discussion by M.E. Rodriguez-Cabazas, P. King, R. Hannon, and S. Ghosh.

\section{REFERENCES}

1. Querinjean P, Masson PL, Heremans JF 1971 Molecular weight, single-chain structure and amino acid composition of human lactoferrin. Eur J Biochem 20:420 425

2. Brock J 1995 Lactoferrin: a multifunctional immunoregulatory protein? Immunol Today 16:417-419

3. Lonnerdal B, Adkins Y 2000 Developmental changes in breast milk protein composition during lactation. In: Sanderson IR, Walker WA (eds) Development of the Gastrointestinal Tract. BC Decker Inc., Hamilton, pp 227-244.

4. Broxmeyer HE, Smithyman A, Eger RR, Meyers PA, de Sousa M 1978 Identification of lactoferrin as the granulocyte-derived inhibitor of colony-stimulating activity production. J Exp Med 148:1052-1067

5. Brines RD, Brock JH 1983 The effect of trypsin and chymotrypsin on the in vitro antimicrobial and iron-binding properties of lactoferrin in human milk and bovine colostrum. Unusual resistance of human apolactoferrin to proteolytic digestion. Biochim Biophys Acta 759:229-235

6. Sanderson IR, Walker WA 1993 Uptake and transport of macromolecules by the intestine: possible role in clinical disorders (an update). Gastroenterology 104:622639

7. Hutchens TW, Henry JF, Yip TT 1991 Structurally intact (78-kDa) forms of maternal lactoferrin purified from urine of preterm infants fed human milk: identification of a trypsin-like proteolytic cleavage event in vivo that does not result in fragment dissociation. Proc Natl Acad Sci U S A 88:2994-2998

8. Mikogami T, Heyman M, Spik G, Desjeux JF 1994 Apical-to-basolateral transepithelial transport of human lactoferrin in the intestinal cell line HT-29cl. 19A. Am J Physiol 267:G308-G315

9. Suzuki YA, Shin K, Lonnerdal B 2001 Molecular cloning and functional expression of a human intestinal lactoferrin receptor. Biochemistry 40:15771-15779

10. Penco S, Pastorino S, Bianchi-Scarra G, Garre C 1995 Lactoferrin down-modulates the activity of the granulocyte macrophage colony-stimulating factor promoter in interleukin-1 beta-stimulated cells. J Biol Chem 270:12263-12268
11. Crouch SP, Slater KJ, Fletcher J 1992 Regulation of cytokine release from mononuclear cells by the iron-binding protein lactoferrin. Blood 80:235-240

12. Oh SM, Hahm DH, Kim IH, Choi SY 2001 Human neutrophil lactoferrin transactivates the matrix metalloproteinase 1 gene through stress-activated MAPK signaling modules. J Biol Chem 276:42575-42579

13. Kanyshkova TG, Semenov DV, Buneva VN, Nevinsky GA 1999 Human milk lactoferrin binds two DNA molecules with different affinities. FEBS Lett 451:235237

14. He J, Furmanski P 1995 Sequence specificity and transcriptional activation in the binding of lactoferrin to DNA. Nature 373:721-724

15. Britigan BE, Lewis TS, Waldschmidt M, McCormick ML, Krieg AM 2001 Lactoferrin binds CpG-containing oligonucleotides and inhibits their immunostimulatory effects on human B cells. J Immunol 167:2921-2928

16. Hartmann G, Weeratna RD, Ballas ZK, Payette P, Blackwell S, Suparto I, Rasmussen WL, Waldschmidt M, Sajuthi D, Purcell RH, Davis HL, Krieg AM 2000 Delineation of a $\mathrm{CpG}$ phosphorothioate oligodeoxynucleotide for activating primate immune responses in vitro and in vivo. J Immunol 164:1617-1624

17. Ohno Y, Lee J, Fusunyan RD, MacDermott RP, Sanderson IR 1997 Macrophage inflammatory protein-2: chromosomal regulation in rat small intestinal epithelial cells. Proc Natl Acad Sci U S A 94:10279-10284

18. Kerneis S, Bogdanova A, Kraehenbuhl JP, Pringault E 1997 Conversion by Peyer's patch lymphocytes of human enterocytes into $\mathrm{M}$ cells that transport bacteria. Science 277:949-952

19. Takeshita F, Leifer CA, Gursel I, Ishii KJ, Takeshita S, Gursel M, Klinman DM 2001 Cutting edge: role of Toll-like receptor 9 in CpG DNA-induced activation of human cells. J Immunol 167:3555-3558

20. Baker EN, Rumball SV 1977 Crystallographic data for human lactoferrin. J Mol Biol 11:207-210

21. Anderson BF, Baker HM, Norris GE, Rumball SV, Baker EN 1990 Apolactoferrin structure demonstrates ligand-induced conformational change in transferrins. Nature 344:784-787

22. Garre C, Bianchi-Scarra G, Sirito M, Musso M, Ravazzolo R 1992 Lactoferrin binding sites and nuclear localization in K562(S) cells. J Cell Physiol 153:477-482

23. Pedersen G, Andresen L, Matthiessen MW, Rask-Madsen J, Brynskov J 2005 Expression of Toll-like receptor 9 and response to bacterial $\mathrm{CpG}$ oligodeoxynucleotides in human intestinal epithelium. Clin Exp Immunol 141:298-306

24. Vazquez-Torres A, Fang FC 2000 Cellular routes of invasion by enteropathogens Curr Opin Microbiol 3:54-59

25. Schubbert R, Renz D, Schmitz B, Doerfler W 1997 Foreign (M13) DNA ingested by mice reaches peripheral leukocytes, spleen, and liver via the intestinal wall mucosa and can be covalently linked to mouse DNA. Proc Natl Acad Sci U S A 94:961-966

26. Kimura H, Cook PR 2001 Kinetics of core histones in living human cells: little exchange of $\mathrm{H} 3$ and $\mathrm{H} 4$ and some rapid exchange of H2B. J Cell Biol 153:13411353

27. Corbett AH, Koepp DM, Schlenstedt G, Lee MS, Hopper AK, Silver PA 1995 Rnalp, a Ran/TC4 GTPase activating protein, is required for nuclear import. J Cell Biol 130:1017-1026

28. Lim CR, Kimata Y, Oka M, Nomaguchi K, Kohno K 1995 Thermosensitivity of green fluorescent protein fluorescence utilized to reveal novel nuclear-like compartments in a mutant nucleoporin NSP1, J Biochem (Tokyo) 118:13-17

29. Sidorova JM, Mikesell GE, Breeden LL 1995 Cell cycle-regulated phosphorylation of Swi6 controls its nuclear localization. Mol Biol Cell 6:1641-1658 